\title{
соцИоЛОГИЯ
}

DOI: $10.17805 /$ ggz.2019.4.7

\section{Маргинальность как социальное явление: трактовка Роберта Парка}

A. В. Кочетков

Московский гуманитарнылй университет

В статье рассматриваются смысл и назначение понятия «маргинальность» в трактовке Роберта Парка. Показано, что «маргинальный человек» Р. Парка находится в состоянии конфликта и раздвоения, а его действия детерминированы неспособностью к адаптаџчи к новой культуре.

Ключевые слова: маргинальность; маргинальный человек; миграция; сочииология культурь

\section{Marginality as a Social Phenomenon: Robert Park's Interpretation}

\author{
A. V. Kochetkov
}

Moscow University for the Humanities

The article discusses the meaning and purpose of the concept of marginality in Robert Park's interpretation. It is shown that the "marginal man" of R. Park is in a state of conflict and bifurcation, and his actions are determined by his inability to adapt to a new culture.

Keywords: marginality; marginal man; migration; sociology of culture

\section{ВВЕДЕНИЕ}

В настоящее время в связи с распространением и достаточно произвольным употреблением понятия маргинальности необходимо не просто уточнить его содержание, а систематизировать различные подходы и аспекты его использования. Поэтому одной из задач, стоящих перед этой статьей, является анализ той части истории развития термина и рассмотрение особенностей его использования, которые связаны с Чикагской социологической школой, где понятие маргинальности оказалось и эффективным структурным элементом основной концепции школы - социальной экологии (Луков, Тихомиров, 2019), и основой особой концепции в социологии культуры, сложившейся позже, уже в конце XX - начале XXI в.

Несмотря на то, что история термина сравнительно коротка, она наполнена не только разнообразными предположениями и поисками, но и 
оригинальными интеллектуальными находками. В этом смысле адекватному пониманию термина «маргинальность» способствуют приданная ему Чикагской школой «методологическая универсальность, применимость к изучению многих социальных процессов, разнообразие контекстов употребления...» (Попова, 1999: 63). Концепция маргинальности «каждый раз приобретала новое звучание и даже порой новый смысл, демонстрируя в то же время эвристическую плодотворность» (там же).

\section{ВЗГЛЯДЫ Р. ПАРКА НА ПРОБЛЕМУ МАРГИНАЛЬНОСТИ}

В философии, социологии, социальной психологии, культурологии понятие маргинальности базируется на результате межкультурных этнических конфликтов и, как следствие, социальных и политических процессов (Попова, 1996). Эта связь учитывалась и тогда, когда Р. Парк определил маргинальность как «случайный продукт процесса аккультурации, который неизбежно происходит тогда, когда народы разных культур и разных рас объединяются, дабы вести общую жизнь» (Park, 1937: XIV; пер. цит. по: Парк, 1998: 175). Но уже с самого начала в категории маргинальности, обстоятельно рассматриваемой Парком (Park, 1928), видятся конкретные задачи его времени и стремление даже в общих категориях осмыслить реальные обстоятельства повседневности Чикаго как города, быстрый рост которого шел за счет эмигрантов. Актуальным в то время было выявление социальнопсихологических последствий образа жизни мигрантов в условиях непривычной для них, обычно сельских жителей, городской среды. Парк удачно применил в возникшей проблемной ситуации идею Г. Зиммеля рассмотреть тип «чужака» как некую социальную универсалию (Николаев, 1998). А следующие после него исследователи смогли показать, что культурная маргинальность является одним из видов маргинальности. Здесь важны исследования У. Томаса и Ф. Знанецкого. В 1937 г. Э. Стоунквист опубликовал свою монографию «Маргинальный человек» с предисловием Р. Парка, где концепция маргинальности представлена в ее теоретической форме (Stonequist, 1937). В итоге концепция окончательно закрепилась в социологии (Феофанов, 1992).

Следует отметить, что Р. Парк известен исследованиями городской среды и ее влияния на человека, а также расовых отношений межкультурного взаимодействия, что объясняет специфику его подхода при изучении данного явления. Влияние на Р. Парка оказали труды 3. Фрейда, а также исследования Г. Зиммеля, характерной особенностью которых стало внимание к психологическим аспектам рассматриваемого явления, «растворение фиксированных содержаний в терминах внутреннего душевного опыта» (Яр- 
ская-Смирнова, 1997: 13). Так что в рамках Чикагской школы отношение к маргинализации носило междисциплинарный характер, во всяком случае с конца 1920-1930-х гг.

Необходимо сделать важное уточнение: слово «маргинальный» употребляется в научной литературе сразу в двух значениях (это связано с этимологией указанного слова, которое в переводе с латинского (“margo") значит «край», «граница»). В политологической, социально-экономической литературе, в обыденном употреблении под этим словом понимается ситуация, когда нечто или некто находится на периферии или границе по отношению к состоянию благополучия в стандартном его понимании. При этом слово «маргинальный» в подобном контексте употребляется, как правило, для демонстрации негативной оценки ситуации. Р. Парк, рассуждая о маргинальности, пользуется вторым значением слова - он говорит о том, что некто находится не на краю, а между: между двумя культурными мирами (Николаев, 2010). Даже в настоящее время исследователи не всегда способны отделить эти значения друг от друга, однако именно трактовка «маргинальности» по Р. Парку стала классической.

Интересно, что, говоря о необходимости оценки природы маргинальности, Р. Парк вводит понятие морального смятения, которое является следствием новых культурных контактов индивида и проявляет себя в достаточно явных формах. Фактически изучение этих форм может позволить не только выявить точки слияния и взаимовоздействия культур, но и более подробно проанализировать процессы прогресса и развития цивилизации.

Особенной чертой понятия маргинальности в данном контексте является его связь с мобильностью населения. Она отражала и реалии того времени: связь маргинальности с мобильностью населения проявлялась в том, что отказ от старых привычек был связан прежде со сменой места жительства и перехода в другое состояние, характеризуемого как кризис. Фактически маргинальность квалифицировалась как «побочный продукт» процесса включения. В условиях «цифрового» общества такие выводы требуют переосмысления, их невозможно уже напрямую применять к оценке отдельных стран или социальных общностей. Но общая конструкция остается той же: сущность маргинальности в рамках «классической» социальноэкологической теории Парка заключается в остром чувстве раздвоения и конфликта, моральной дихотомии, ощущении того, что старые привычки уже потеряли свою актуальность, а новые, необходимые для данной среды, еще не сформировались (Park, 1950). 


\section{«МАРГИНАЛЬНЫЙ ЧЕЛОВЕК» Р. ПАРКА}

В представлениях Р. Парка наиболее очевидным примером маргинального человека выступает иммигрант, т. е. человек, который живет сразу «в двух мирах» - как христианский новообращенный в странах Азии и Африки. В этой связи природа маргинального человека определяется тем чувством конфликта и морального раздвоения, когда уже принято решение об отказе от старых привычек, а новые привычки еще не сформированы. Подобное состояние является одним из следствий перехода из одного мира в другой, который можно рассматривать как кризис. Сам ученый в этой связи отмечает, что «периоды перехода и кризиса в жизни большинства из нас сравнимы с теми, которые переживает иммигрант, когда он покидает родину, чтобы искать фортуну в чужой стране. Но в случае маргинального человека период кризиса относительно непрерывный. В результате он имеет тенденцию превращаться в тип личности» (Park, 1950: 355-356; пер. цит. по: Попова, 1999: 67).

При этом нельзя утверждать, что миграция является единственным и уникальным механизмом формирования ситуаций, в которых проявляется маргинальность. В некоторых трудах Р. Парка упоминаются и иные ситуации (помимо миграции), к их числу можно отнести, например, войны и завоевания, торговые обмены и т. д. Все эти ситуации схожи в том, что они одновременно создают условия для взаимного проникновения культур и последовательного уничтожения границ, разделяющих эти культуры.

Р. Парк рассматривал маргинальную личность как некий социальный объект, находящийся на стыке нескольких культур и обществ, которые никогда полностью не соединятся, и, как следствие, такой субъект не будет принят в новообразованное общество и останется в нем личностью с разделенным сознанием и психическим расстройством.

Описывая особенности статуса маргинального человека, глава Чикагской школы социологии часто использует психологические характеристики индивида. Известный американский психолог Т. Шибутани попытался систематизировать те черты личности маргинального человека, которые упоминались или описывались Р. Парком в его исследованиях. В системе черт личности маргинального человека Т. Шибутани указал следующее:

- наличие сомнений в ценности своей личности и в ценности собственных суждений;

- неопределенность дружеских и любовных связей;

- неспособность наслаждаться жизнью в любых ее проявлениях;

- постоянная боязнь быть отвергнутым и ярко выраженная боязнь одиночества;

- боязнь осуществления разнообразных рискованных предприятий; 
- привычка избегать любых неопределенных состояний и ситуаций;

- болезненная застенчивость, остро проявляющая в присутствии малознакомых людей;

- чрезмерное беспокойство о будущем и т. д. (Шибутани, 1999).

При этом Р. Парк отмечал, что концепция маргинального человека опирается не на специфику личностных типов людей, а на социальные процессы. Согласно этой точке зрения, маргинальный человек представляет собой «побочный продукт» процесса аккультурации в ситуациях, когда представители разнообразных культур и рас объединяются для продолжения взаимного существования. В этом смысле более перспективным является изучение маргинальности с точки зрения общества, частью которого является маргинальный человек (Park, 1950).

Определение маргинального человека, данное Парком, таково: «Маргинальный человек - это личностный тип, который возникает там и тогда, где и когда из конфликта рас и культур рождаются новые общества, народы и культуры. Та же самая судьба, которая обрекает его жить одновременно в двух мирах, принуждает его принять в отношении тех миров, в которых он живет, роль космополита и чужака. На фоне своей культурной среды он неизбежно становится индивидом с более широким кругозором, более тонким интеллектом, более отстраненной и рациональной точкой зрения. Маргинальный человек - это всегда человек сравнительно более цивилизованный» (Park, 1937: XIII; пер. цит. по: Парк, 1998: 175). Такая трактовка маргинального человека «дает возможность иначе взглянуть на назначение этой фигуры в социальных практиках повседневности. У Парка и других представителей Чикагской школы это, несомненно, позитивная фигура, что в дальнейшем было утеряно, а маргинал стал рассматриваться как фигура, опасная в своей неукорененности и несоциализированности» (Луков, 2018: 226).

\section{ЗАКЛЮЧЕНИЕ}

Одним из ключевых итогов исследований Р. Парка в области маргинализации стал его вывод о том, что появление маргинальных личностей является следствием возникновения новых типов культурных взаимоотношений, которые формируются на новом уровне цивилизации в результате взаимопроникновения культур и развития глобализации (Баньковская, 1994). Следовательно, рассмотрение проблем маргинальности связано у Парка с «культурологическим подходом».

После 1934 г. многие идеи Чикагской школы отошли в тень, и социология многие годы связывалась со структурным функционализмом. Но времена меняются, и снова к маргинализации ключ дает концепция Р. Парка. 
Ее переосмысление с учетом изменившихся реалий способно дать немало плодотворных идей современным исследователям.

\section{СПИСОК ЛИТЕРАТУРЫ}

Баньковская, С. П. (1994) Роберт Парк // Современная американская социология / под ред. В. И. Добренькова. М. : Изд-во Моск. ун-та. 296 с. С. 3 19.

Луков, В. А. (2018) Тезаурусная социология : в 4 т. М. : Изд-во Моск. гуманит. ун-та. Т. 1.608 с.

Луков, В. А., Тихомиров, Д. А. (2019) Чикагская социологическая школа: начало качественной стратегии в эмпирической социологии [Электронный ресурс] // Горизонты гуманитарного знания. № 1. C. 89-107. URL: http://journals.mosgu.ru/ggz/article/view/953 (дата обращения: 11.08.2019). DOI: 10.17805/ggz.2019.1.5

Николаев, В. Г. (1998) Человек «на границе»: проблема маргинальности в зеркале социологической классики (Проблема маргинальности: ее структурный контекст и социально-психологические импликации) // Социальные и гуманитарные науки. Отечественная и зарубежная литература. Серия 11: Социология. № 2. С. 156-172.

Николаев, В. Г. (2010) Человек маргинальный // Вопросы социальной теории : научных альманах. Т. 4: Человек в поисках идентичности / Ин-т философии РАН ; под ред. Ю. М. Резника, М. В. Тлостановой. М. : Ассоциация «Междисциплинарное общество социальной теории». 528 с. С. 354-372.

Парк, Р. Э. (1998) Культурный конфликт и маргинальный человек // Социальные и гуманитарные науки. Отечественная и зарубежная литература. Серия 11: Социология. № 2. С. 172-175.

Попова, И. П. (1996) Маргинальность. Социологический анализ : учеб. пособие. М. : Союз. 77 с.

Попова, И. П. (1999) Новые маргинальные группы в российском обществе (теоретические аспекты исследования) // Социальные исследования. № 7. С. 62-71.

Феофанов, К. А. (1992) Социальная маргинальность: характеристика основных концепций и подходов в современной социологии : обзор // Общественные науки за рубежом. Серия 11: Социология. № 2. С. 70-83.

Шибутани, Т. (1999) Социальная психология / пер. с англ. В. Б. Ольшанского. М. : АСТ ; Ростов н/Д : Феникс. 539 с.

Ярская-Смирнова, Е. Р. (1997) Социокультурный анализ нетипичности. Саратов : Изд-во СГТУ. 272 с.

Park, R. E. (1928) Human migration and the marginal man // American Journal of Sociology. Vol. 33. No. 6. P. 881-893. 
Park, R. E. (1937) Introduction // Stonequist E. V. The marginal man: A study in personality and culture conflict. N. Y. : Russell \& Russell ; Charles Scribner's Sons. xviii, 228 p. P. XIII-XVIII.

Park, R. E. (1950) Race and culture. Glencoe, IL : The Free Press. xxii, 403 p.

Stonequist, E. V. (1937) The marginal man: A study in personality and culture conflict. N. Y. : Russell \& Russell ; Charles Scribner's Sons. xviii, 228 p.

Дата поступления: 15.09.2019 2.

\section{REFERENCES}

Bankovskaia, S. P. (1994) Robert Park. In: Sovremennaia amerikanskaia sotsiologiia [Contemporary American sociology] / ed. by V. I. Dobrenkov. Moscow : Moscow University Publ. 296 p. Pp. 3-19. (In Russ.).

Lukov, V. A. (2018) Tezaurusnaia sotsiologiia [Thesaurus sociology] : in 4 vols. Moscow : Moscow University for the Humanities Publ. Vol. 1. 608 p. (In Russ.).

Lukov, V. A. and Tikhomirov, D. A. (2019) Chikagskaia sotsiologicheskaia shkola: nachalo kachestvennoi strategii v empiricheskoi sotsiologii [The Chicago school of sociology: The rise of the qualitative strategy in empirical sociology]. Gorizonty gumanitarnogo znaniia, no. 1, pp. 89-107. [online] Available at: http:// journals.mosgu.ru/ggz/article/view/953 (accessed 11.08.2019). (In Russ.). DOI: 10. 17805/ggz.2019.1.5

Nikolaev, V. G. (1998) Chelovek «na granitse»: problema marginal'nosti v zerkale sotsiologicheskoi klassiki (Problema marginal'nosti: ee strukturnyi kontekst i sotsial'no-psikhologicheskie implikatsii) [Man "on the border": The issue of marginality in the mirror of sociological classics (The problem of marginality: Its structural context and socio-psychological implications]. Sotsial'nye $i$ gumanitarnye nauki. Otechestvennaia $i$ zarubezhnaia literatura. Seriia 11: Sotsiologiia, no. 2, pp. 156-172. (In Russ.).

Nikolaev, V. G. (2010) Chelovek marginal'nyi [Marginal man]. In: Voprosy sotsial'noi teorii [Issues of social theory] : An academic almanac. Vol. 4: Chelovek $v$ poiskakh identichnosti [Man in search for identities] / Institute of Philosophy, RAS ; ed. by Yu. M. Reznik and M. V. Tlostanova. Moscow : Assotsiatsiia «Mezhdistsiplinarnoe obshchestvo sotsial'noi teorii» [Association "Interdisciplinary Society of Social Theory"]. 528 p. Pp. 354-372. (In Russ.).

Park, R. E. (1998) Kul'turnyi konflikt i marginal'nyi chelovek [Cultural conflict and the marginal man]. Sotsial'nye i gumanitarnye nauki. Otechestvennaia i zarubezhnaia literatura. Seriia 11: Sotsiologii, no. 2, pp. 172-175. (In Russ.). 
Popova, I. P. (1996) Marginal'nost'. Sotsiologicheskii analiz [Marginality. A sociological analysis] : A study guide. Moscow : Soiuz Publ. 77 p. (In Russ.).

Popova, I. P. (1999) Novye marginal'nye gruppy v rossiiskom obshchestve (teoreticheskie aspekty issledovaniia) [New marginal groups of the Russian society (Theoretical aspects of the research)]. Sotsial'nye issledovaniia, no. 7, pp. 62-71. (In Russ.).

Feofanov, K. A. (1992) Sotsial'naia marginal'nost': kharakteristika osnovnykh kontseptsiî i podkhodov v sovremennoi sotsiologii : obzor [Social marginality: Characteristics of the main concepts and approaches in contemporary sociology: A review]. Obshchestvennye nauki za rubezhom. Seriia 11: Sotsiologiia, no. 2, pp. 70-83. (In Russ.).

Shibutani, T. (1999) Sotsial'naia psikhologiia [Social psychology] / transl. from English by V. B. Olshanskii. Moscow : AST Publ. ; Rostov-on-Don : Feniks Publ. 539 p. (In Russ.).

Iarskaia-Smirnova, E. R. (1997) Sotsiokul'turnyi analiz netipichnosti [Sociocultural analysis of atypicality]. Saratov : Saratov State Technical University Publ. 272 p. (In Russ.).

Park, R. E. (1928) Human migration and the marginal man. American Journal of Sociology, vol. 33, no. 6, pp. 881-893.

Park, R. E. (1937) Introduction. In: Stonequist E. V. The marginal man: A study in personality and culture conflict. New York : Russell \& Russell ; Charles Scribner's Sons. xviii, 228 p. Pp. XIII-XVIII.

Park, R. E. (1950) Race and culture. Glencoe, IL : The Free Press. xxii, 403 p.

Stonequist, E. V. (1937) The marginal man: A study in personality and culture conflict. New York : Russell \& Russell ; Charles Scribner’s Sons. xviii, 228 p.

Submission date: 15.09.2019.

Кочетков Антон Витальевич - аспирант Московского гуманитарного университета. Адрес: 111395, Россия, г. Москва, ул. Юности, 5. Тел.: +7 (499) 374-60-21. Эл. адрес: ak@stroyka.group

Kochetkov Anton Vitalievich, postgraduate student, Moscow University for the Humanities. Postal address: 5 Yunosti St., 111395 Moscow, Russian Federation. Tel.: +7 (499) 374-60-21. E-mail: ak@stroyka.group

Для ичитирования:

Кочетков А. В. Маргинальность как социальное явление: трактовка Роберта Парка [Электронный ресурс] // Горизонты гуманитарного знания. 2019. № 4. C. 96-103. URL: http://journals.mosgu.ru/ggz/article/view/1063 (дата обращения: дд.мм.гггг). DOI: 10.17805/ggz.2019.4.7 